\title{
Global critical natural assets
}

Rebecca Chaplin-Kramer ${ }^{* 1,2}$, Rachel A Neugarten ${ }^{3,4}$, Richard P Sharp ${ }^{1}$, Pamela M Collins ${ }^{4}$, Stephen Polasky ${ }^{5}$, David Hole ${ }^{4}$, Richard Schuster ${ }^{6,7}$, Matthew Strimas-Mackey ${ }^{3}$, Mark Mulligan $^{8}$, Carter Brandon $^{9}$, Sandra Diaz ${ }^{10,11}$, Etienne Fluet-Chouinard ${ }^{12}$, Larry Gorenflo ${ }^{13}$, Justin A Johnson ${ }^{5}$, Patrick W Keys ${ }^{14}$, Kate Longley-Wood ${ }^{15}$, Peter B McIntyre ${ }^{3}$, Monica Noon ${ }^{4}$, Unai Pascual ${ }^{16,17,18}$, Catherine Reidy Liermann ${ }^{19}$, Patrick R Roehrdanz ${ }^{4}$, Guido SchmidtTraub $^{20,21}$, M. Rebecca Shaw ${ }^{22}$, Mark Spalding ${ }^{15,23}$, Will R Turner ${ }^{4}$, Arnout van Soesbergen ${ }^{24,8}$, Reg A Watson ${ }^{25}$

*Correspondence to: bchaplin@ stanford.edu

${ }^{1}$ Natural Capital Project, Stanford University, 327 Campus Drive, Stanford CA USA

${ }^{2}$ Institute on the Environment, University of Minnesota, 1954 Buford Ave, St. Paul, MN, USA

${ }^{3}$ Dept. of Natural Resources \& Environment, Cornell University, 226 Mann Drive, Ithaca NY 14853

USA

${ }^{4}$ Conservation International, 2100 Crystal Drive \#600, Arlington, VA 22202, USA

${ }^{5}$ Dept. of Applied Economics, University of Minnesota, St. Paul, MN 55108, USA

${ }^{6}$ Dept. of Biology, 1125 Colonel By Drive, Carleton University, Ottawa ON, K1S 5B6 Canada.

${ }^{7}$ Ecosystem Science and Management Program, 3333 University Way, University of Northern

British Columbia, Prince George BC, V2N 4Z9 Canada.

${ }^{8}$ Dept. of Geography, King's College London, Bush House, North East Wing, 40 Aldwych, London, WC2B 4BG, UK

${ }^{9}$ World Resources Institute, 10 G St NE \#800, Washington, DC 20002

${ }^{10}$ Consejo Nacional de Investigaciones Científicas y Técnicas, Instituto Multidisciplinario de

Biología Vegetal (IMBIV), CONICET, Casilla de Correo 495, 5000 Córdoba, Argentina.

${ }^{11}$ Universidad Nacional de Córdoba, Facultad de Ciencias Exactas, Físicas y Naturales, Departamento de Diversidad Biológica y Ecología, Córdoba, Argentina.

${ }^{12}$ Dept. of Earth System Science, Stanford University, 473 Via Ortega, Stanford, CA, 94305, USA

${ }^{13}$ Dept. of Landscape Architecture, Penn State University, University Park, PA 16802, USA

${ }^{14}$ School of Global Environmental Sustainability, Colorado State University, Mailstop 1036, Fort Collins CO 80523

${ }^{15}$ The Nature Conservancy, 4245 Fairfax Drive, Arlington, VA 22203, USA

${ }^{16}$ Basque Centre for Climate Change, Sede Building 1, 1st floor. Scientific Campus of the University of the Basque Country, 48940 Leioa, Spain

${ }^{17}$ Basque Foundation for Science, Ikerbasque, Bilbao, Spain

${ }^{18}$ Centre for Development and Environment, University of Bern, Bern, Switzerland

${ }^{19}$ Department of Environmental Science, Huxley College, Western Washington University, Everett, WA 98201, USA

${ }^{20}$ Sustainable Development Solutions Network, 19 Rue Bergère, 75009 Paris France.

${ }^{21}$ Sunway University, 5, Jalan Universiti, Bandar Sunway, 47500 Petaling Jaya, Selangor, Malaysia

${ }^{22}$ World Wildlife Fund, San Francisco, CA 94105, USA.

${ }^{23}$ Dept. of Physical, Earth, and Environmental Sciences, University of Siena, Pian dei Mantellini, Siena 53100, Italy

${ }^{24}$ UN Environment World Conservation Monitoring Centre, 219 Huntingdon Road, Cambridge, CB3 ODL, United Kingdom

${ }^{25}$ Institute for Marine and Antarctic Studies, University of Tasmania, 20 Castray Esplanade, Battery Point, Tasmania, Australia 7004 
Abstract: Sustaining the organisms, ecosystems, and processes that underpin human well-being is necessary to achieve sustainable development. Here we analyze 12 of nature's contributions to people (NCP) for food, water, and climate security. Using spatial optimization, we identify critical natural assets, the most important ecosystems for providing NCP, comprising $39 \%$ of total global land area and $24 \%$ of national territorial waters. Many of these NCP are overlooked by international agreements focused on conserving species or mitigating climate change, yet our analysis shows that explicitly prioritizing critical natural assets jointly advances development, climate, and conservation goals. Developing policy and investment strategies that protect critical natural assets is essential for securing Earth's life support systems.

One Sentence Summary: Global optimization shows 39\% of land and 24\% of ocean area contains $90 \%$ of current levels of provision for 12 of nature's contributions to people.

\section{Main Text:}

Human actions are rapidly transforming the planet, driving losses of nature at an unprecedented rate that negatively impacts societies and economies - from accelerating climate change to increasing zoonotic pandemic risk $(1,2)$. Recognizing the accelerating severity of the environmental crisis, in 2015 the global community committed to the Sustainable Development Goals (SDGs) and the Paris Agreement on climate change. In 2021, the UN Convention on Biological Diversity (CBD) will convene governments to adopt new targets for conserving, restoring and sustainably managing all dimensions of biodiversity, including nature's contributions to people (NCP) (3). Collectively, these three policy frameworks will shape the sustainable development agenda for the next decade. All three depend heavily on safeguarding natural assets, the living components of our lands and waters. For instance, restoring and ending conversion and degradation of forests, wetlands and peatlands will sequester $9 \mathrm{Gt} \mathrm{CO}_{2}$ per year by 2050 (4). Natural assets also underpin most of the SDG targets (1). While ambitious new targets to protect species and ecosystems have been proposed, including "half earth" (conserving half the earth's area for nature) (5) and " 30 by 30" (30\% of land and ocean protected by 2030) (6), these targets have been criticized for insufficiently accounting for the needs of people, which is critical for gaining support for broad-scale conservation (7).

Despite the urgency of safeguarding natural assets, understanding of the geography of the critical benefits provided by ecosystems is limited. Without spatial information on NCP, governments cannot identify synergies or reduce trade-offs between development, climate, and biodiversity objectives (8), businesses cannot manage supply chain risks efficiently, and communities cannot target protections for the ecosystems on which they most depend. Here we identify the planet's critical natural assets and show how these ecosystems provide important local benefits while also contributing to global goals.

Advances in data availability and computational power enable us to model 12 NCP globally (Fig. 1a), representing the most comprehensive analysis at a fine spatial scale $(300 \mathrm{~m}$, resampled to 2 $\mathrm{km})$ to date $(9,10)$. These $12 \mathrm{NCP}$ were chosen to span development, biodiversity and climate goals, and to be mappable with spatially explicit data representing the period 2000-2015. They include contributions related to water quality and regulation; provision of food, energy, and raw materials; climate risk reduction; and recreational benefits (Fig. S1a). We conduct our analysis at the country level, recognizing that national governments implement strategies to pursue goals under international agreements, and we aggregate results globally. 
We attribute the magnitude of nature's contributions and, where possible, the number of people potentially benefiting, to the ecosystems providing those contributions - a key step in identifying critical natural assets. We define natural assets as the inland and marine waters and natural and semi-natural terrestrial ecosystems (including working lands like rangelands and production forests, but excluding cropland, urban areas, bare areas, and permanent snow and ice). To synthesize across the $12 \mathrm{NCP}$, we use integer linear programming to identify the minimum areas within each country's borders and marine Exclusive Economic Zones (EEZs) that support target level (ranging from 5\% to 100\%) of every NCP. We define "critical" natural assets using the $90 \%$ target, beyond which far more area is required to reach higher levels of NCP. Finally, we evaluate how well nationally-prioritized critical natural assets align spatially with global-scale priorities, including terrestrial ecosystem carbon storage, atmospheric moisture cycling, terrestrial vertebrate biodiversity, and human cultural diversity (Fig. S1b).

Critical natural assets that provide $90 \%$ of current levels of each of the 12 NCP assessed (Fig. 1a) are concentrated in only $39 \%\left(53,068,128 \mathrm{~km}^{2}\right)$ of total land area (excluding Antarctica) and $24 \%\left(34,047,596 \mathrm{~km}^{2}\right)$ of countries' marine EEZs, reflecting the steep slope of the aggregate NCP accumulation curve (Fig. 1b). Within individual countries, NCP accumulation curves indicate that encompassing $90 \%$ of all NCP requires $0.3 \%$ to $87 \%$ of land area and $2 \%$ to $90 \%$ of EEZ area (Fig. S2). This high variability in the NCP-area relationship is partially driven by human population density; countries with both large population centers and vast expanses with few people, such as Canada and Russia, have NCP accumulation curves that reach $90 \%$ of NCP with the least area (10\% and $20 \%$ of land, respectively). The slope of NCP accumulation curves are also driven by heterogeneity of ecosystem types across climate gradients; greater diversity of ecosystems yields higher levels of NCP in a smaller proportion of area, as in Chile and Australia.

Critical natural asset "hotspots" (highest-contributing areas, denoted by the darkest blue or green shades in Fig. 1c) often coincide with diverse and relatively intact habitat near or upstream from large numbers of people. However, some hotspots also arise in areas with low population density but substantial water resources that benefit downstream population centers, such as Appalachia in the United States or the western highlands of China, highlighting that critical natural assets can sometimes be spatially distant from their beneficiaries.

Unlike the NCP prioritized here at country scales, the benefits of carbon storage accrue globally; we therefore present overlaps between areas with globally high levels of carbon storage and the other $12 \mathrm{NCP}$, rather than combining them in the country-level optimization. Conserving 39\% of land area as critical natural assets that support $90 \%$ of current levels of provision across each of the 12 NCP would also secure 39\% of global terrestrial ecosystem (above- and below-ground and soil) carbon (Table 1). This proportionality indicates that NCP prioritized at a country level is not an adequate surrogate for a global NCP like carbon storage. Synergies may still exist in 40 many regions of the world, though; nearly half of the $39 \%$ of land area identified as critical natural assets overlaps with the highest carbon storage areas (Fig. 2). In supplementary analyses, we find that many patterns shown here are similar, whether prioritized at a national or global scale (Fig. S3), but including carbon storage in the optimization increases the area requirements by up to $20 \%$ (Fig. S4). 
bioRxiv preprint doi: https:/doi org/10.1101/2020 11.08 361014 this version posted November 9,2020 . The copyright holder for this preprint (which was not certified by peer review) is the author/funder, who has granted bioRxiv a license to display the preprint in perpetuity. It is made available under aCC-BY-NC 4.0 International license.

\begin{tabular}{|c|c|c|c|c|}
\hline $\begin{array}{l}\text { a. } \\
\text { List of Nature's Contribution to People (NCP) modeled }\end{array}$ & b. 100 & \multicolumn{3}{|r|}{$=\times \bullet$} \\
\hline Nitrogen retention for water quality regulation & & • : & $=$ & \\
\hline Sediment retention for water quality regulation & 80 & & " & \\
\hline Crop pollination & $\begin{array}{l}\text { Z } 70 \\
\bar{\pi}\end{array}$ & $\therefore x \times$ & & \\
\hline Fodder for livestock & $\frac{0}{0} 60$ & $\bullet x=1$ & & \\
\hline Timber production & $\frac{ \pm}{0} 50$ & $\bullet x=$ & & \\
\hline Fuelwood production & $\div 40$ & $\bullet x=$ & & - Ocean (within EEZ) \\
\hline Flood regulation & 30 & oxim & & - Land \\
\hline Riverine fish harvest & 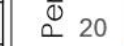 & $\propto$ & & $\times$ Total area \\
\hline Marine fish harvest & 10 & $\infty$ & & \\
\hline Coastal risk reduction (terrestrial and marine) & 0 & $\infty$ & 39 & \\
\hline Access to terrestrial nature (for local recreation and gathering) & & 0 & & 100 \\
\hline Marine recreation (coral-reef tourism and associated livelihoods) & & & & \\
\hline
\end{tabular}

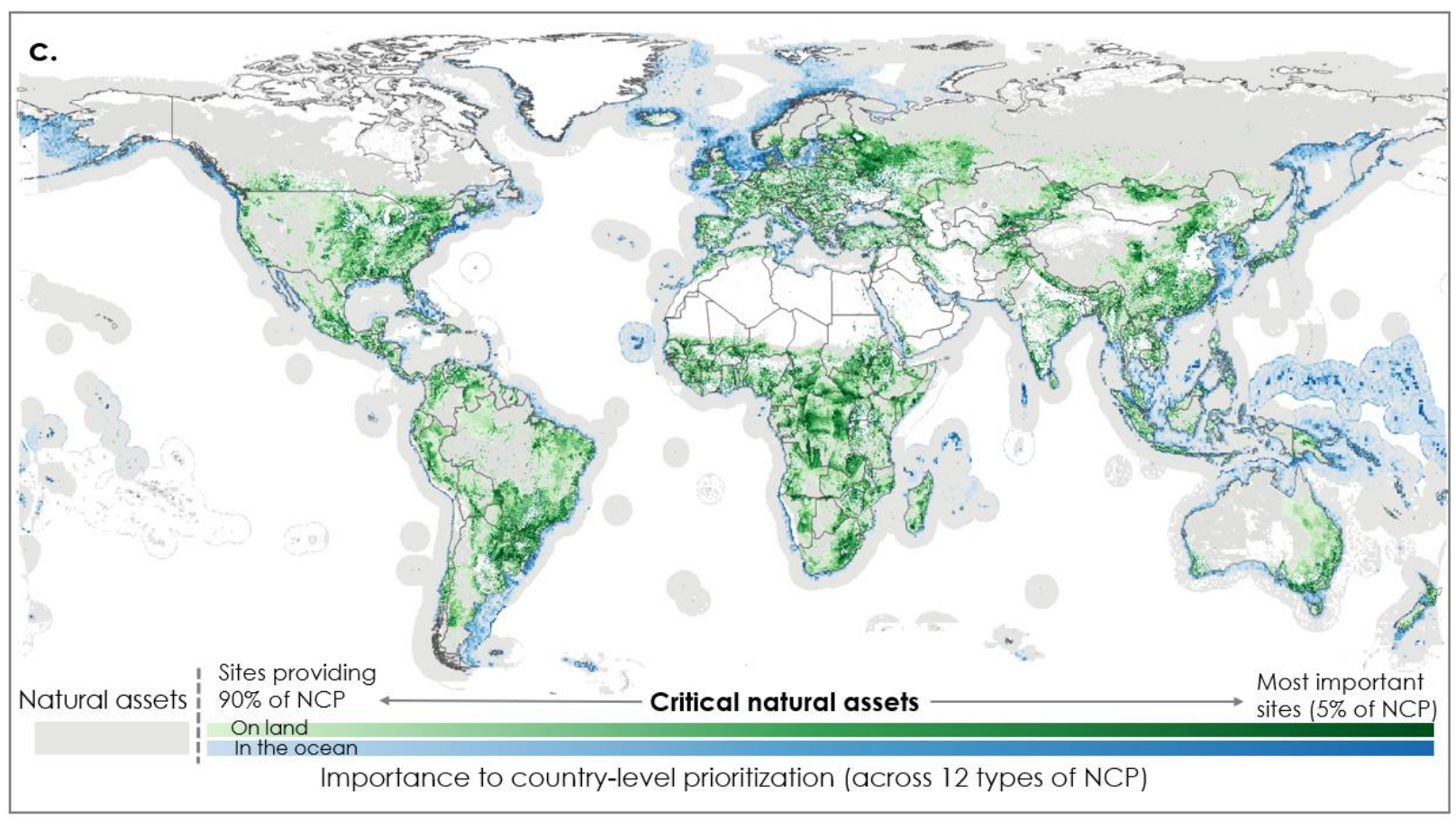

Figure 1. Critical natural assets, defined as the natural and semi-natural terrestrial and aquatic ecosystems required to maintain nature's contributions to people (NCP) on land (green) and in the ocean (blue). (a) The 12 NCP analyzed. (b) The NCP accumulation curve reflecting the total area required to maintain target levels of all NCPs in every country, with dotted lines denoting the area of critical natural assets (90\% of NCP in 39\% of land area and 24\% of EEZ area). Areas selected by optimization within each country are aggregated across all countries to create a single curve; see Fig. S2 for individual country curves. (c) Map of critical natural assets, with darker shades connoting greater contribution to aggregate NCP. Grey areas show the extent of remaining natural assets not designated "critical" but included in this analysis (excluding cropland, urban and bare areas, permanent ice, and areas outside the EEZ). 


\begin{tabular}{|l|l|l|}
\hline NCP Target & $\mathbf{5 0} \%$ & $\mathbf{9 0} \%$ \\
\hline \% Land Area & $14 \%$ & $39 \%$ \\
\hline \% Carbon Storage & $14 \%$ & $39 \%$ \\
\hline \% Moisture Recycling & $24 \%$ & $64 \%$ \\
\hline \% Languages & $84 \%$ & $97 \%$ \\
\hline \% Terrestrial biodiversity & $59 \%$ & $82 \%$ \\
\hline
\end{tabular}

Table 1. Overlaps between nature's contributions to people $(N C P)$ prioritized at a country level and other priorities more relevant at a global level. The percent of total ecosystem carbon storage, atmospheric moisture recycling, cultural (language) diversity and terrestrial vertebrate biodiversity coinciding with natural assets are presented for different target levels $(50 \%$ and 90\%) of NCP on land.

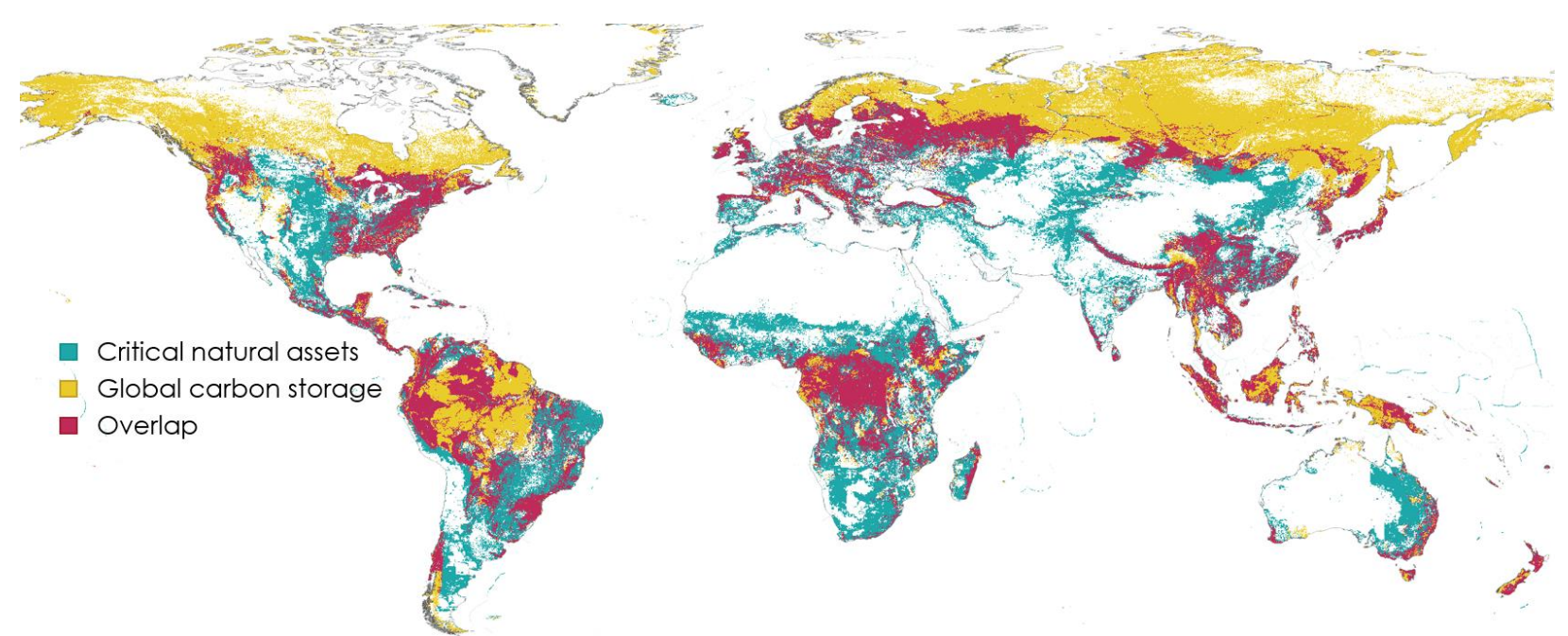

Figure 2. Spatial overlaps between country-level critical natural assets and global terrestrial carbon storage. Gold and teal denote where high carbon storage areas or critical natural assets (areas providing $90 \%$ of all $12 \mathrm{NCP}$ listed in Fig 1), but not both, occur; red shows areas where the two overlap (45\% of the area of each). To identify the highest carbon storage areas, we selected locations with the highest terrestrial carbon storage for the same land area as required by critical natural assets (39\%). These areas make up 65\% of total terrestrial carbon storage.

Other global scale priorities (moisture recycling, biodiversity, cultural diversity) show greater spatial overlap with nationally-prioritized NCP (Table 1). Critical natural assets that provide

$2090 \%$ of all NCP also contribute $64 \%$ of atmospheric moisture recycling (modeled at a 1.5 degree resolution, too coarse for the optimization). Biodiversity shows even higher overlap, with $82 \%$ of 26,709 terrestrial vertebrates represented by critical natural assets for part or all of their Area of Habitat ( $\mathrm{AOH}$, based on species range maps, habitat preferences and elevation (see SM Methods) (11)). Critical natural assets also cover areas representing $97 \%$ of global indigenous and non-migrant languages, a measure of cultural diversity (12). 
While these $12 \mathrm{NCP}$ are not comprehensive of all the ways people benefit from and value nature (1), our analysis includes the three groups of NCP explicitly mentioned in the negotiating text of the CBD's post-2020 Global Biodiversity Framework (GBF) (13): food security (pollination, grazing, and marine and riverine fisheries), water security (water quality regulation from sediment retention and nitrogen retention), and disaster risk reduction (riverine flood mitigation and coastal protection). We also address several material and non-material contributions to wellbeing that are currently missing from the GBF (timber, fuelwood, recreation). This information advances beyond recently published maps of biodiversity and carbon (14), and our multi-NCP optimization approach could accommodate additional NCP (such as open-ocean fisheries and non-material benefits such as learning, inspiration, spirituality and cultural identities) as spatial data become available at sufficient resolution and at the appropriate scale.

In our NCP mapping, we represent the realized benefits of natural assets - weighted by beneficiary population when feasible - but this understates the range of ways in which natural assets directly and indirectly benefit people. Limited socio-economic data and paucity of reliable models linking NCP to welfare measures preclude more precise valuation of most NCP at a global scale. Additional insight could be gained from mapping natural assets that support the most vulnerable people, including indigenous peoples whose culture directly depend on natural assets, and the global poor who lack the ability to procure substitutes. Linking NCP modeling with integrated assessment modeling and general equilibrium economic modeling could translate the benefits of critical natural assets to GDP outcomes (15), and reveal telecoupling between countries arising from transboundary benefits or via global trade (16). At the same time, remote sensing and machine learning are elucidating the geography of built (or "grey") infrastructure (17), enabling more compelling assessments of the role of natural assets. In many cases, critical natural assets probably produce synergies with anthropogenic assets (3), which should be accounted for as societies make decisions about protecting NCP.

Our approach could be extended beyond current NCP delivery to prioritize restoration of natural assets (18) and identify ecosystems whose NCP may become more important under projected global change (e.g., mitigating disaster risk from climate change or population shifts impacting demand for NCP). Also, the urban and cropland systems that were omitted from this analysis (given lack of detailed global, spatial land management data) provide essential contributions to people, and future work could consider gains from sustainably managing and restoring these systems. Interdependencies and feedbacks between NCP within and between regions should also be considered for more robust scenario planning. For example, the productivity of rangelands, forests, and rainfed croplands throughout much of South America depends on precipitation from atmospheric moisture recycling by Amazonian forests (19). Reduced precipitation could lead to ecological tipping points and NCP collapse in those dependent ecosystems (20).

$40 \quad$ Our analysis enables national and global leaders to identify critical natural assets, priority areas for maintaining a wide range of NCP. Though global analyses can increasingly account for the geography of both natural assets and beneficiaries of NCP, they should be replicated at national scales, with local data and complemented by input from local experts and diverse stakeholders to ensure accuracy and public legitimacy $(21,22)$. Prioritizing for NCP would provide a rigorous foundation to enable international financing for climate mitigation, biodiversity conservation and sustainable development to also address the needs of local people, allowing low-income 
countries to secure the most critical areas for their citizens. We find it encouraging that optimizing the protection of $90 \%$ of critical natural assets would require an area comparable to other proposed conservation targets $(5,6)$. Thus, quantifying and mapping critical natural assets is a vital step forward in empowering actors at all levels to make decisions that benefit both nature and people.

\section{References and Notes}

1. S. Díaz et al., "Summary for policymakers of the global assessment report on biodiversity and ecosystem services of the Intergovernmental Science-Policy Platform on Biodiversity and Ecosystem Services" (2019).

2. A. P. Dobson et al., Ecology and economics for pandemic prevention. Science. 369, 379$381(2020)$.

3. S. Diaz et al., Assessing nature's contributions to people. Science. 359, 270-272 (2018).

4. S. Roe et al., Contribution of the land sector to a $1.5^{\circ} \mathrm{C}$ world. Nat. Clim. Chang. 9 (2019).

5. E. O. Wilson, Half-earth: Our Planet's Fight for Life (WW Norton \& Company, 2016).

6. J. Baillie, Y.-P. Zhang, Space for nature. Science. 361, 1051 (2018).

7. B. Büscher et al., Half-Earth or Whole Earth? Radical ideas for conservation, and their implications. Oryx. 51, 407-410 (2017).

8. G. Schmidt-Traub et al., Integrating climate, biodiversity, and sustainable land-use strategies: innovations from China. Natl. Sci. Rev. (2020), doi:10.1093/nsr/nwaa139.

9. R. Chaplin-Kramer et al., Global modeling of nature's contributions to people. Science. 258, 255-258 (2019).

10. S. S. Myers et al., Human health impacts of ecosystem alteration. Proc. Natl. Acad. Sci. U. S. A. 110, 201218656 (2013).

11. T. M. Brooks et al., Measuring terrestrial area of habitat (AOH) and its utility for the IUCN Red List. Trends Ecol. Evol. 34, 977-986 (2019).

12. L. J. Gorenflo, S. Romaine, R. A. Mittermeier, K. Walker-Painemilla, Co-occurrence of linguistic and biological diversity in biodiversity hotspots and high biodiversity wilderness areas. Proc. Natl. Acad. Sci. 109, 8032-8037 (2012).

13. Convention on Biodiversity, "Zero draft of the post-2020 global biodiversity framework.

Released for peer review January 2020. CBD/WG2020/2/3.Add1” (2020).

14. M. Jung et al., bioRxiv, in press, doi:10.1101/2020.04.16.021444.

15. J. A. Johnson et al., Global Futures: Modelling the Global Economic Impacts of Environmental Change to Support Policy Making (2020).

16. K. E. Kapsar et al., Telecoupling research: The first five years. Sustainability. 11, 1033 (2019).

17. M. Mulligan, A. van Soesbergen, L. Sáenz, GOODD, a global dataset of more than 38,000 georeferenced dams. Sci. Data. 7, 1-8 (2020).

18. J. D. Allan et al., Using cultural ecosystem services to inform restoration priorities in the Laurentian Great Lakes. Front. Ecol. Environ. 13, 418-424 (2015).

19. P. W. Keys, L. Wang-Erlandsson, L. J. Gordon, Revealing Invisible Water: Moisture Recycling as an Ecosystem Service. PLoS One. 11, e0151993 (2016).

20. V. Dakos et al., Ecosystem tipping points in an evolving world. Nat. Ecol. Evol. 3, 355362 (2019).

21. L. Mandle et al., Assessing ecosystem service provision under climate change to support conservation and development planning in Myanmar. PLoS One. 12, e0184951 (2017). 
22. R. A. Neugarten et al., Trends in protected area representation of biodiversity and ecosystem services in five tropical countries. Ecosyst. Serv. 42, 101078 (2020).

\section{Acknowledgments}

We thank all the participants of two working groups hosted by Conservation International and the Natural Capital Project for their insight and intellectual contributions, and for further advise or assistance provided by Alison Adams, Katrina Brandon, Kate Brauman, Abigail Cramer, Gretchen Daily, Jon Fisher, Rachelle Gould, Christina Kennedy, Lisa Mandle, Jamie Montgomery, Amanda Rodewald, David Rossiter, Elizabeth Selig, Adrian Vogl, and T. Max Wright. Funding: the two working groups that provided the foundation for this analysis were funded by the Marcus and Marianne Wallenberg Foundation and a grant provided by Betty and Gordon Moore. Authors contributions: RCK, RPS, MM, EFC, LG, PWK, KLW, PBM, MN, CRL, PRR, MS, AvS, and RAW provided data, RS and MSM performed the optimizations, RCK, RPS, LG, and PRR performed additional analyses, CB, SD, UP, GST, MRS, and WRT provided framing for policy relevance, RCK, RAN, PMC, SP, and DH directed the project, RCK and RAN wrote the first draft of the paper, and all authors contributed to revisions. Competing interests: the authors declare no competing interests. Data and materials availability: All final outputs and code are available on Open Science Framework: https://osf.io/r5xz7/. All links to individual data layers feeding into the optimization are listed in the Supplementary Materials.

\section{Supplementary Materials}

Materials and Methods

Fig S1 - S4

References 23-95 